Open Access

\title{
Clinical-grade mesenchymal stem cells derived from umbilical cord improve septic shock in pigs
}

Caroline Laroye ${ }^{1,2,3,4^{*}}$, Jérémie Lemarié ${ }^{2,4,5}$, Amir Boufenzer ${ }^{6}$, Pierre Labroca ${ }^{5}$, Lisiane Cunat ${ }^{4,7}$, Corentine Alauzet ${ }^{4,7}$, Frédérique Groubatch ${ }^{4,8}$, Clémence Cailac ${ }^{9}$, Lucie Jolly ${ }^{2,4,6}$, Danièle Bensoussan ${ }^{1,3,4}$, Loïc Reppel ${ }^{1,3,4}$ and Sébastien Gibot ${ }^{2,4,5}$

\author{
* Correspondence: \\ caroline.laroye@univ-lorraine.fr \\ ${ }^{1} \mathrm{CHRU}$ de Nancy, Unité de Thérapie \\ Cellulaire et banque de tissus, 54500 \\ Vandoeuvre-lès-Nancy, France \\ ${ }^{2}$ INSERM, U1116, 54500 \\ Vandoeuvre-lès-Nancy, France \\ Full list of author information is \\ available at the end of the article
}

\begin{abstract}
Background: Septic shock is the leading cause of death in intensive care units. The pathophysiological complexity of this syndrome contributes to an absence of specific treatment. Several preclinical studies in murine models of septic shock have shown improvements to organ injury and survival after administration of mesenchymal stem cells (MSCs). To better mimic a clinical approach in humans, we investigated the impact of randomized controlled double-blind administration of clinical-grade umbilical cord-derived MSCs to a relevant pig model of septic shock.
\end{abstract}

Methods: Septic shock was induced by fecal peritonitis in 12 male domestic pigs. Animals were resuscitated by an experienced intensivist including fluid administration and vasopressors. Four hours after the induction of peritonitis, pigs were randomized to receive intravenous injection of thawed umbilical cord-derived MSCS (UCMSC) $\left(1 \times 10^{6}\right.$ UCMSCs $/ \mathrm{kg}$ diluted in $75 \mathrm{~mL}$ hydroxyethyl starch (HES), $(n=6)$ or placebo (HES alone, $n=6$ ). Researchers were double-blinded to the treatment administered. Hemodynamic parameters were continuously recorded. Gas exchange, acid-base status, organ function, and plasma cytokine concentrations were assessed at regular intervals until $24 \mathrm{~h}$ after the onset of peritonitis when animals were sacrificed under anesthesia.

Results: Peritonitis induced profound hypotension, hyperlactatemia, and multiple organ failure. These disorders were significantly attenuated when animals were treated with UCMSCs. In particular, cardiovascular failure was attenuated, as attested by a better mean arterial pressure and reduced lactatemia, despite lower norepinephrine requirements. As such, UCMSCs improved survival in this very severe model $60 \%$ survival vs. $0 \%$ at $24 \mathrm{~h}$ ).

Conclusion: UCMSCs administration is beneficial in this pig model of polymicrobial septic shock.

Keywords: Septic shock, Mesenchymal stem cells, Umbilical cord, Clinical-grade

\section{Background}

Sepsis, defined as life-threatening organ dysfunction caused by a deregulated host response to infection, is a leading cause of admission to intensive care units and is associated with high mortality rates $[1,2]$. Unfortunately, due to the extremely complex

(c) The Author(s). 2018 Open Access This article is distributed under the terms of the Creative Commons Attribution 4.0 International License (http://creativecommons.org/licenses/by/4.0/), which permits unrestricted use, distribution, and reproduction in any medium, provided you give appropriate credit to the original author(s) and the source, provide a link to the Creative Commons license, and indicate if changes were made. 
physiopathology of sepsis and septic shock, there is still no specific treatment for this syndrome. Indeed, in the initial stages, simultaneous production of pro-inflammatory and anti-inflammatory mediators is observed [3, 4], and thus, it is now accepted that sepsis is not a succession of hyper- and hypo-inflammatory states, but that the two are intertwined. This new paradigm may explain the failure of many therapies targeting this deregulated host response [5].

Among emerging treatments, mesenchymal stem cells (MSCs) appear as promising candidates to treat sepsis and septic shock. MSCs are characterized as non-hematopoietic stem cells, capable of differentiating into chondrocytes, adipocytes, and osteocytes. Their extensive immunomodulatory properties mean they can modulate inflammatory and immune disorders [6-8]. Mei et al. [9] were the first to suggest that MSCs improve survival and organ failure in a mouse model of endotoxemia. The mechanism responsible for the protective action of MSC during septic shock is unclear but appears to be multifactorial. Several studies indicated that MSCs can increase bacterial clearance [10] and modulate cytokine production by decreasing pro-inflammatory mediators and increasing anti-inflammatory cytokines [11-16]. Finally, through their immunomodulatory capacities and antibacterial properties, they can improve renal, pulmonary, liver, cardiac, and muscular function, as well as coagulopathy associated with septic shock [11, 17-21].

However, these studies mostly used MSCs derived from adult tissues (bone marrow and adipose tissue). Adult MSCs present many drawbacks with regard to their potential for clinical applications; the number of adult MSC donors is limited, and adult MSC remain difficult to produce [22]. In contrast, fetal tissues, and particularly umbilical cord (UC), appear to have greater potential as sources of MSCs. Umbilical cord can be donated without risk and is abundantly available. Moreover, MSCs are present in large numbers in the UC, and they can be rapidly and quite easily expanded [23].

In this study, we performed a randomized controlled double-blind investigation to examine the effect of the administration of thawed clinical-grade UC-derived MSCs in a relevant pig model of septic shock resuscitated by an experienced intensivist. We hypothesized that clinical-grade UCMSC would improve hemodynamic parameters and septic shock-induced organ injury.

\section{Methods}

\section{UCMSC production}

Umbilical cords were collected at Nancy Maternity Hospital from new mothers who had signed an informed consent form in compliance with French national legislation regarding human sample collection, manipulation, and personal data protection. The collection protocol was approved by the local ethics committee and the French ministry for research (No. DC-2014-2114). All UCMSCs were produced at clinical-grade in $\alpha$-MEM culture medium (Macopharma, Mouvaux, France) enriched with 5\% platelet lysate (Macopharma, Mouvaux, France) and applying good manufacturing practices. Briefly, UCs were immersed in an antibiotic-antifungal solution composed of gentamicin, amoxicillin, vancomycin, and amphotericin B for $1 \mathrm{~h}$ at room temperature. The cord was then cut into thin pieces which were placed in complete medium. The culture was carried out at $37{ }^{\circ} \mathrm{C}$ and in hypoxic conditions (5\% of $\mathrm{O}_{2}$ and $5 \%$ of $\mathrm{CO}_{2}$ ). UCMSCs were cultured until passage three and then frozen and stored in vapor phase 
nitrogen. After thawing, UCMSCs were washed once in hydroxyethyl starch to remove the cryoprotectant and used within $2 \mathrm{~h}$.

\section{Characterization of UCMSCs}

Once $80 \%$ confluence was reached, UCMSCs were washed with HBSS and detached by trypsinization. To examine expression levels of surface markers, $1 \times 10^{6}$ UCMSCs were labeled with anti-CD90, CD73, CD44, CD105, CD34, CD45, CD11b, CD19, and HLA-DR mAbs (Stemflow hMSC Analysis kit, Becton Dickinson, Franklin Lakes, USA).

Osteogenic and adipogenic differentiation was also performed to characterize MSCs.

Osteogenic differentiation was induced by seeding UCMSCs at a density of 3100 cells/ $\mathrm{cm}^{2}$ and maintaining them in culture for 28 days in an osteogenic induction medium (Lonza, Walkersville, USA). After 28 days, samples were fixed in $4 \%$ paraformaldehyde and then included in paraffin before staining with alizarin red. To induce adipocyte differentiation, 21,000 UCMSCs $/ \mathrm{cm}^{2}$ were seeded on 24-well plates. When $100 \%$ confluence was reached, 3 induction/maintenance cycles were performed. One induction/maintenance cycle consisted in 3-day culture in induction medium (Lonza, Walkersville, USA), followed by 1 to 3 days of culture in maintenance medium (Lonza, Walkersville, USA). After 3 cycles of induction/maintenance, the cells were cultured for 7 days in complete maintenance medium (Lonza, Walkersville, USA) before staining with oil red.

\section{Animal preparation}

Experiments were performed in line with the National Institute of Health guidelines on the Use of Laboratory Animals and were approved by the University Animal Care Committee (Comité d'Éthique Lorrain en Matière d'Expérimentation Animale (CELMEA - CE2A-66), authorization number: APAFIS5674-201606141602993).

Six-month-old male domestic pigs (40-60 kg) were purchased from Elevage Ferry (Vosges, France). Before surgery, animals were fasted overnight with free access to water. Pre-anesthesia was performed by intramuscular administration of ketamine $(10 \mathrm{mg} / \mathrm{kg})$ and midazolam $(0.1 \mathrm{mg} / \mathrm{kg})$. Anesthesia was induced and maintained until the end of the protocol with intravenous propofol $(8 \mathrm{mg} / \mathrm{kg} / \mathrm{h})$, sufentanil $(5 \mu \mathrm{g} / \mathrm{h})$, and cisatracurium $(20 \mathrm{mg} / \mathrm{h}$ ). Animals were mechanically ventilated (tidal volume $8 \mathrm{ml} / \mathrm{kg}$, PEEP $5 \mathrm{~cm} \mathrm{H}_{2} \mathrm{O}, \mathrm{FiO}_{2}$ 0.30, respiratory rate 14-16 breaths/min adjusted to maintain normocapnia). The right jugular vein was exposed, and a triple-lumen line was inserted. A Swan-Ganz catheter was positioned allowing cardiac output, $\mathrm{S}_{\mathrm{v}} \mathrm{O}_{2}$, and right atrial and pulmonary arterial pressure to be continuously recorded. A catheter was inserted in the right carotid artery to continuously measure arterial pressure. A catheter inserted into the bladder was used to collect urine.

After instrumentation, a midline laparotomy was performed to collect feces from the left colon; $3 \mathrm{~g} / \mathrm{kg}$ was suspended in $200 \mathrm{~mL} 0.9 \% \mathrm{NaCl}$ and $50 \mathrm{~mL}$ glucose $5 \%$ and incubated at $37^{\circ} \mathrm{C}$ for $2 \mathrm{~h}$. After surgery, a tube was left in place to induce peritonitis.

Animals were allowed to recover for $2 \mathrm{~h}$ after surgery before performing baseline measurements (defined as "H0"). Normal saline was continuously administered $(10 \mathrm{~mL} / \mathrm{kg} / \mathrm{h})$ throughout the study. 


\section{Experimental protocol}

After collecting baseline data (H0), peritonitis was induced by administering autologous feces through the abdominal tube which was subsequently clamped. After $4 \mathrm{~h}(\mathrm{H} 4)$, animals were randomly assigned to groups to receive $1 \times 10^{6} \mathrm{UCMSCs} / \mathrm{kg}$ diluted in $75 \mathrm{~mL}$ hydroxyethyl starch (HES) $(n=6)$ or HES alone $(n=6)$ through the intravenous catheter. Cells or starch were administered over $10 \mathrm{~min}$.

The intensivist in charge of the animal was blinded to the treatment administered, which was prepared by an independent investigator.

Animal care was provided by an experienced intensive care physician who adhered strictly to the following guidelines throughout the study period:

i) Hemodynamic targets. The main objective was to maintain mean arterial pressure (MAP) above $85 \mathrm{mmHg}$. To achieve this goal, $0.9 \% \mathrm{NaCl}$ was administered (up to $20 \mathrm{~mL} / \mathrm{kg}$ ) provided that central venous pressure (CVP) and pulmonary artery occlusion pressure (PAOP) were $<18 \mathrm{mmHg}$. When the maximum volume was reached, continuous infusion of norepinephrine was started up to $10 \mu \mathrm{g} / \mathrm{kg} / \mathrm{min}$.

ii) Respiratory targets. The main objective was to maintain a $\mathrm{PaO}_{2} / \mathrm{FiO}_{2}$ ratio $>300$ and an arterial $\mathrm{PaCO}_{2}$ at 35-45 mmHg. Ventilator settings could thus be modified by increasing inspiratory/expiratory ratio close to $1: 1$, PEEP up to $15 \mathrm{~cm} \mathrm{H}_{2} \mathrm{O}$, and respiratory rate up to 30 breaths/min.

iii) Body temperature was kept constant $\left( \pm 1^{\circ} \mathrm{C}\right)$ using heating pads or cooling.

iv) Intravenous glucose infusion was administered when necessary to maintain glycemia at $5-7 \mathrm{mmol} / \mathrm{L}$.

Animals were sacrificed under deep anesthesia by $\mathrm{KCl}$ infusion $24 \mathrm{~h}$ after the induction of peritonitis or if MAP remained $<50 \mathrm{mmHg}$ during more than $30 \mathrm{~min}$ despite administration of the maximum dose of norepinephrine.

\section{Measurements}

Hemodynamic parameters were continuously monitored including MAP, mean pulmonary artery pressure (MPAP), right atrial pressure (RAP), cardiac output (CO), cardiac index $(\mathrm{CI})$, and $\mathrm{S}_{\mathrm{v}} \mathrm{O}_{2}$.

Blood was sequentially drawn for the determination of (i) blood gases, (ii) arterial lactate, (iii) plasma concentration of urea, creatinine, albumin (VetTest GHP, Idexx, Saint-Denis, France) (iv) blood cell count, and (v) TNF- $\alpha$, and IL-6 (ELISA, RnD Systems, Minneapolis, USA). At the end of the experiment, bacterial counts were performed on blood samples, and lung and kidney biopsies were taken for histological analyses. Histology scores were determined by an experienced pathologist who was blinded to the treatment applied.

\section{Statistics}

After testing for their normal distribution (Kolmogorov-Smirnov test), data were presented as mean \pm SEM. Between-group differences were analyzed for statistical significance by two-way ANOVA for repeated measures, using the Bonferroni correction or Student's $t$ test when appropriate. Statistical analyses were performed using GraphPad Prism software. 


\section{Results}

\section{Characteristics of UCMSCs}

According to the standards described by the International Society for Cellular Therapy [24], the immunophenotype for UCMSCs is CD14 ${ }^{\text {neg }}-C D 34^{\text {neg }}-{ }_{-H L A-D R}{ }^{\text {neg }}-C D 11 b-$ ${ }^{\text {neg }}{ }_{-} \mathrm{CD} 19^{\text {neg }}-\mathrm{CD} 73^{+}-\mathrm{CD} 90^{+}-\mathrm{CD} 105^{+}-\mathrm{CD} 44^{+}$. These cells can also be induced to differentiate into osteocytes and adipocytes (Fig. 1).

\section{UCMSCs attenuate hemodynamic failure associated with septic shock}

Peritonitis induced a rapid drop in MAP (Fig. 2) despite volume resuscitation $(8.16 \mathrm{~mL} / \mathrm{kg} / \mathrm{h}$ for controls vs. $7.48 \mathrm{~mL} / \mathrm{kg} / \mathrm{h}$ for UCMSC group, $p=0.667)$. Therefore, to maintain MAP > $85 \mathrm{mmHg}$, norepinephrine was started by H12 in $4 / 6$ and $1 / 6$ control and UCMSC animals, respectively. The norepinephrine infusion rate required to maintain blood pressure was significantly lower in the UCMSC-treated animals than in controls $(p<0.0001)$ (Fig. 2).

Although no differences were observed between groups for $\mathrm{CO}$ and $\mathrm{HR}, \mathrm{SvO}_{2}$ was significantly improved and lactate concentrations significantly reduced in the group receiving UCMSCs $(p<0.01)$, suggesting lower tissue hypoxia in this group (Fig. 2).
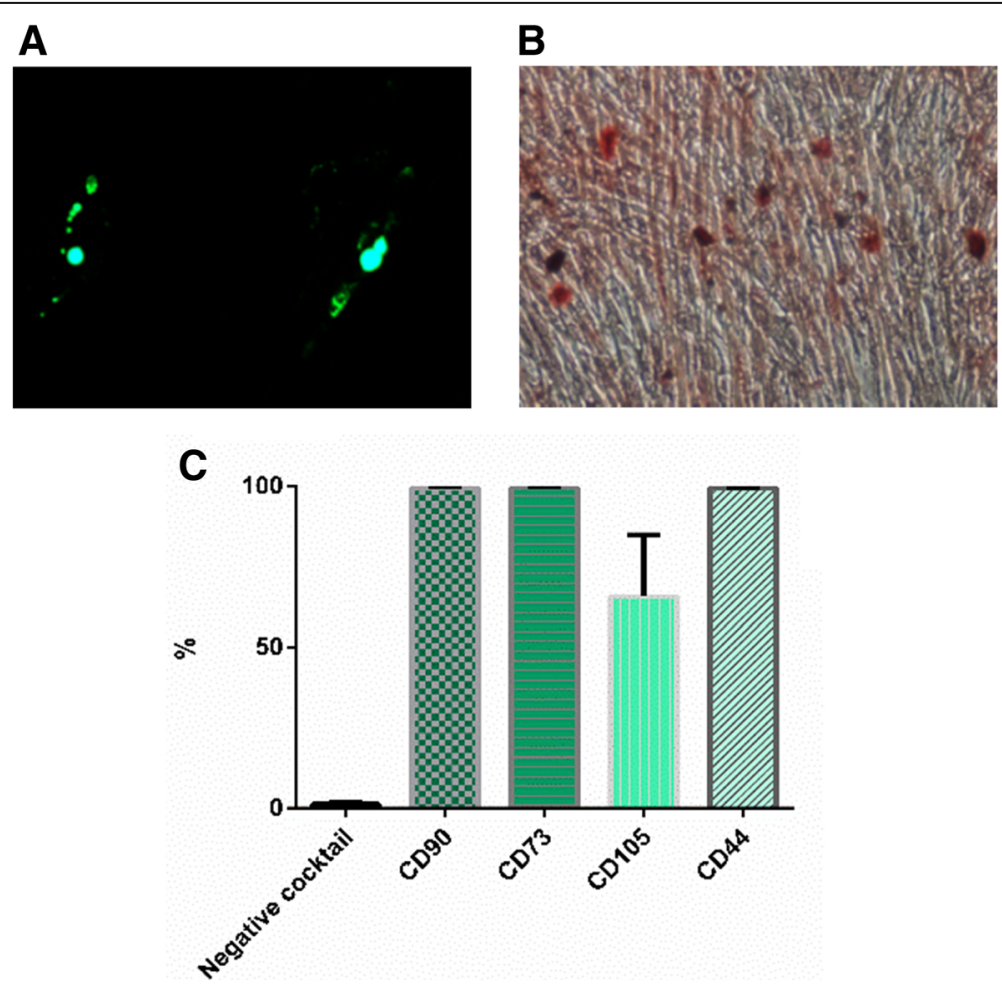

Fig. 1 Characterization of UCMSCs. Mesodermic differentiation of UCMSCS. Clinical-grade UCMSCs differentiated into adipocytes (a) and osteocytes (b). Representative images are shown at $\times 10$ magnification. Immunophenotypic analysis of UCMSCs by flow cytometry (c). UCMSCs presented the typical immunophenotype of MSCs. Negative cocktail includes CD34, CD45, CD11b, CD19, and HLA-DR markers. Results are shown as percentages of positive cells and are expressed as mean \pm SEM. $(n=3)$ 


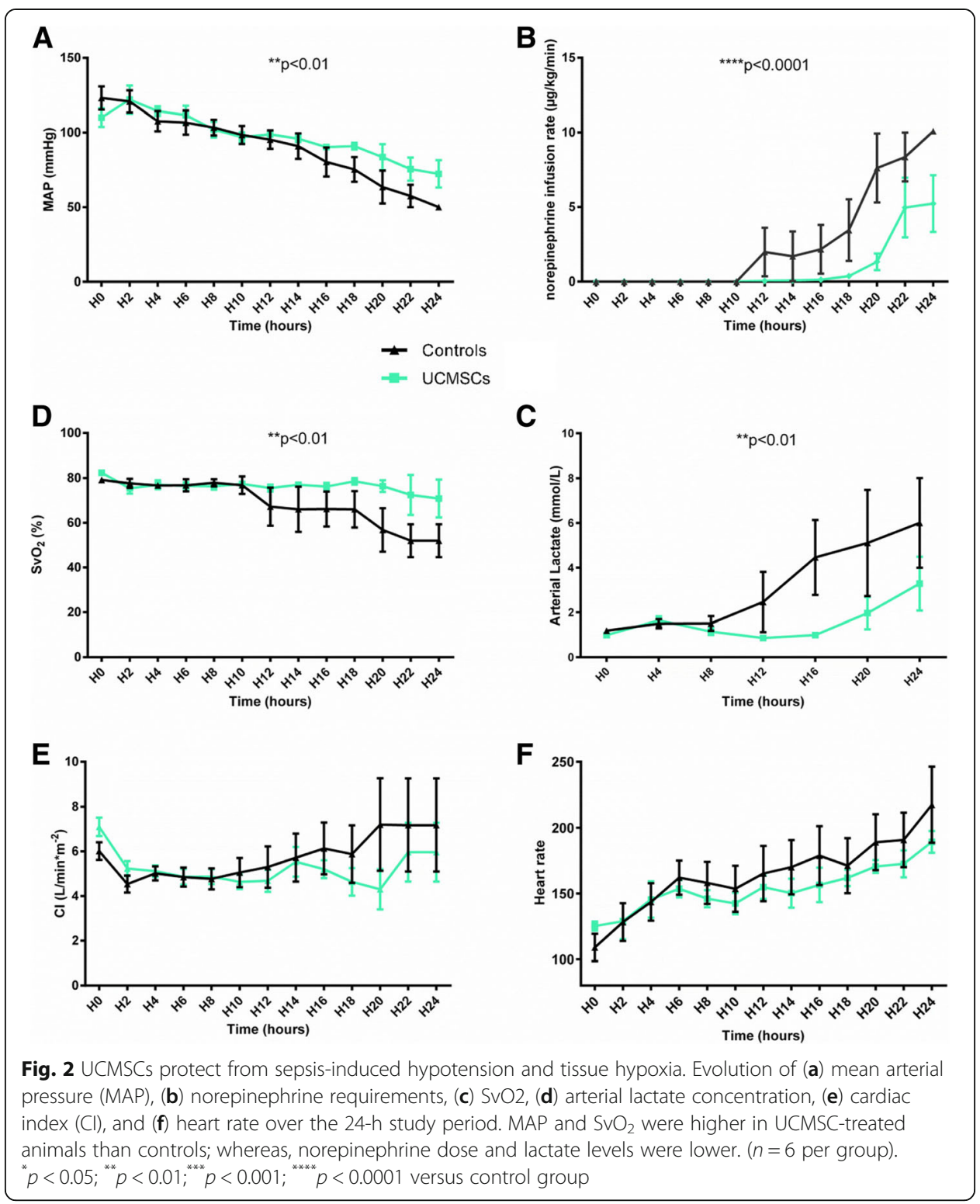

\section{UCMSCs ameliorate organ failure}

Sepsis induced progressive hypoxemia reflected by a decrease in the $\mathrm{PaO}_{2} / \mathrm{FiO}_{2}$ ratio (Fig. 3a). This phenomenon was significantly attenuated in the UCMSC group $(p<0.05)$. Histological observations supported this finding, as reduced inflammatory infiltration and interstitial edema was recorded in treated pigs.

UCMSC administration appears to have a moderate effect on kidney failure. Despite a trend for improved diuresis, and a significantly smaller increase in plasma creatinine $(p<0.01)$ (Fig. 3b), histological examinations revealed no differences between the two groups.

\section{UCMSCs show no antimicrobial effect}

All septic animals were found to be bacteremic. No significant differences were observed between groups. Median bacterial colony-forming unit (CFU) counts were 


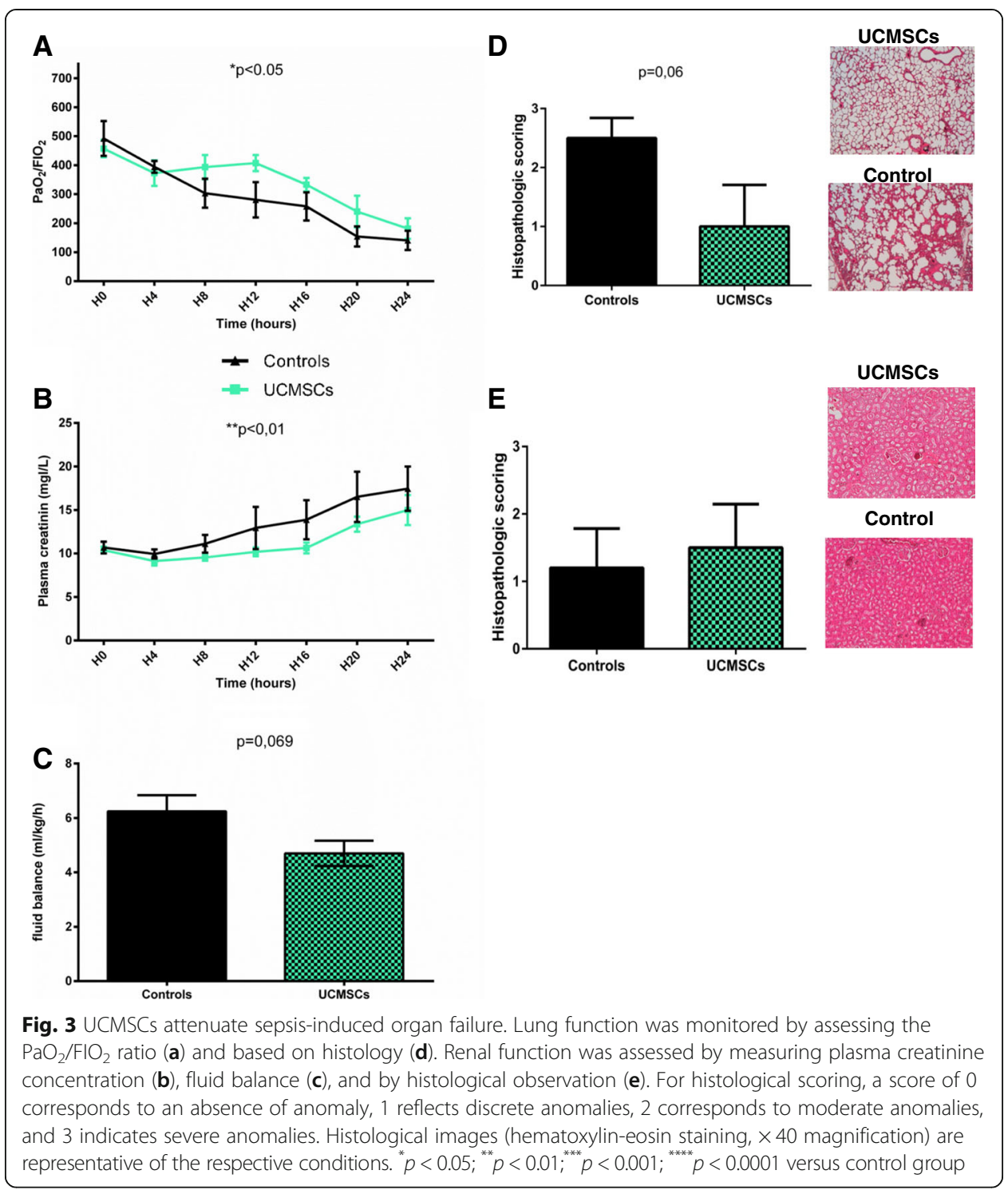

$855 \mathrm{CFU} / \mathrm{ml}$ of blood for controls and $225 \mathrm{CFU} / \mathrm{ml}$ of blood for UCMSC-treated animals (Fig. 4a).

To determine if this result was due to inadequate numbers of infiltrated UCMSC, we tested the antibacterial properties of UCMSC at different concentrations in vitro (Fig. 4b-d). No antimicrobial effect of UCMSCs was observed on the three bacterial species tested.

\section{UCMSCs have no effect on cytokine production}

To determine the impact of UCMSCs on inflammation, we measured plasma concentrations of IL- 6 and TNF $\alpha$. TNF $\alpha$ levels, high at the beginning of study due to the surgical procedure, decreased during the first $4 \mathrm{~h}$ of peritonitis and then stabilized until the end of the protocol. The TNF $\alpha$ profile was similar for both groups (Fig. 5a). IL-6 concentrations progressively increased throughout the study period, 


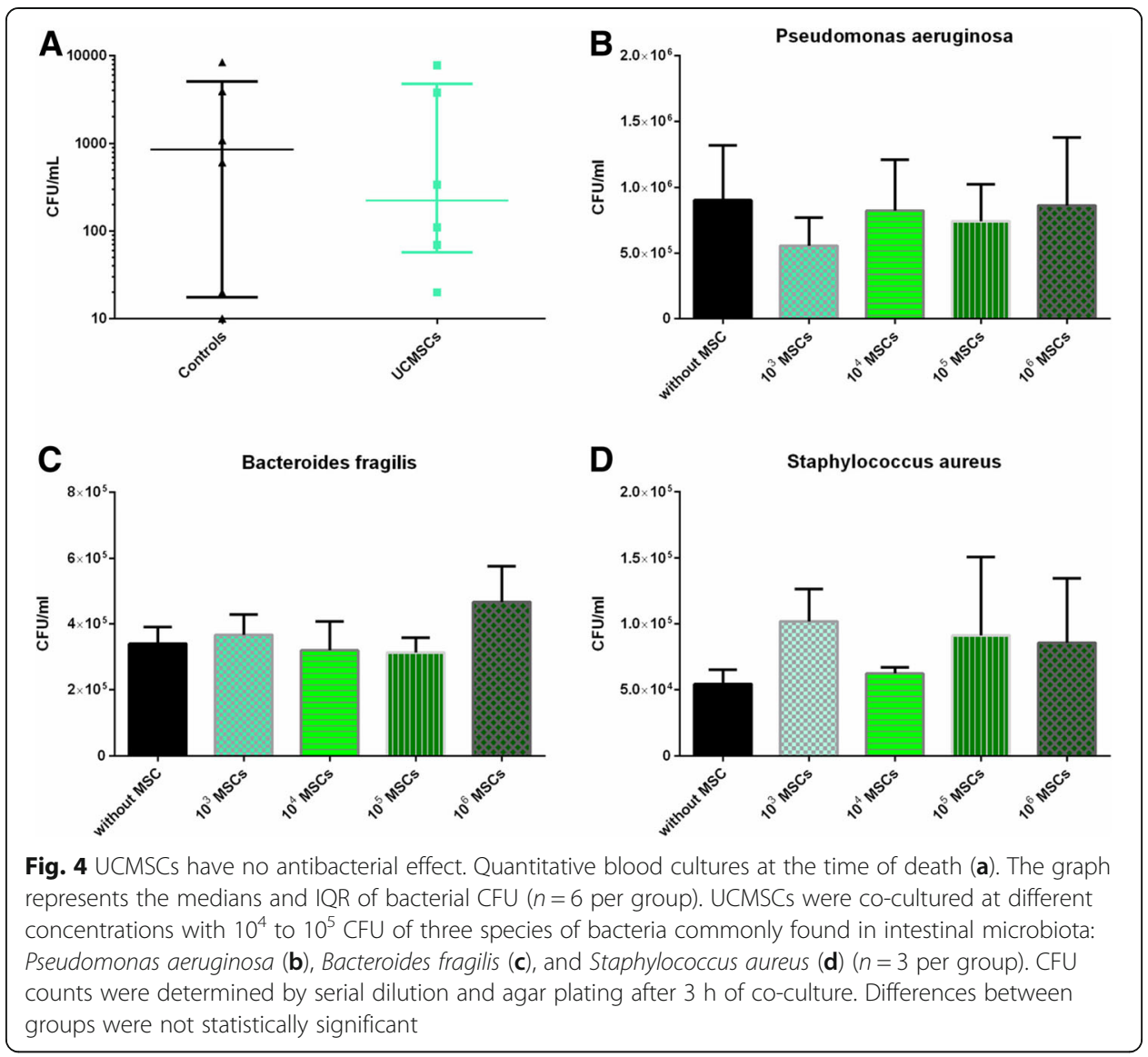

both in the treated and the control groups (Fig. 5b). UCMSCs had no effect on IL-6 or TNF $\alpha$.

\section{UMSCs do not alter blood immune profile}

After induction of peritonitis, slight leukopenia with a drop in granulocyte numbers was observed in both groups; differences were not significant. Thrombocytopenia was also observed, but was not influenced by UCMSC treatment (Table 1).

\section{UCMSCs improve survival}

Twenty-four hours after induction of peritonitis, all control animals had died; whereas in the UCMSC group, $60 \%$ of pigs were still alive at the end of the protocol (Log-rank test, $p=0.08$ ) (Fig. 6).

\section{Discussion}

Many preclinical studies have reported a beneficial effect of administering MSC during septic shock. However, these murine studies did not reflect human clinical practice and generally used MSCs derived from adult tissues (bone marrow and adipose tissue). Here, we tried to avoid these pitfalls and to better mimic a clinical approach in humans. We thus applied a randomized controlled double-blind protocol to investigate the effect of administering thawed clinical-grade UC-derived MSCs in a relevant pig model of septic shock resuscitated 

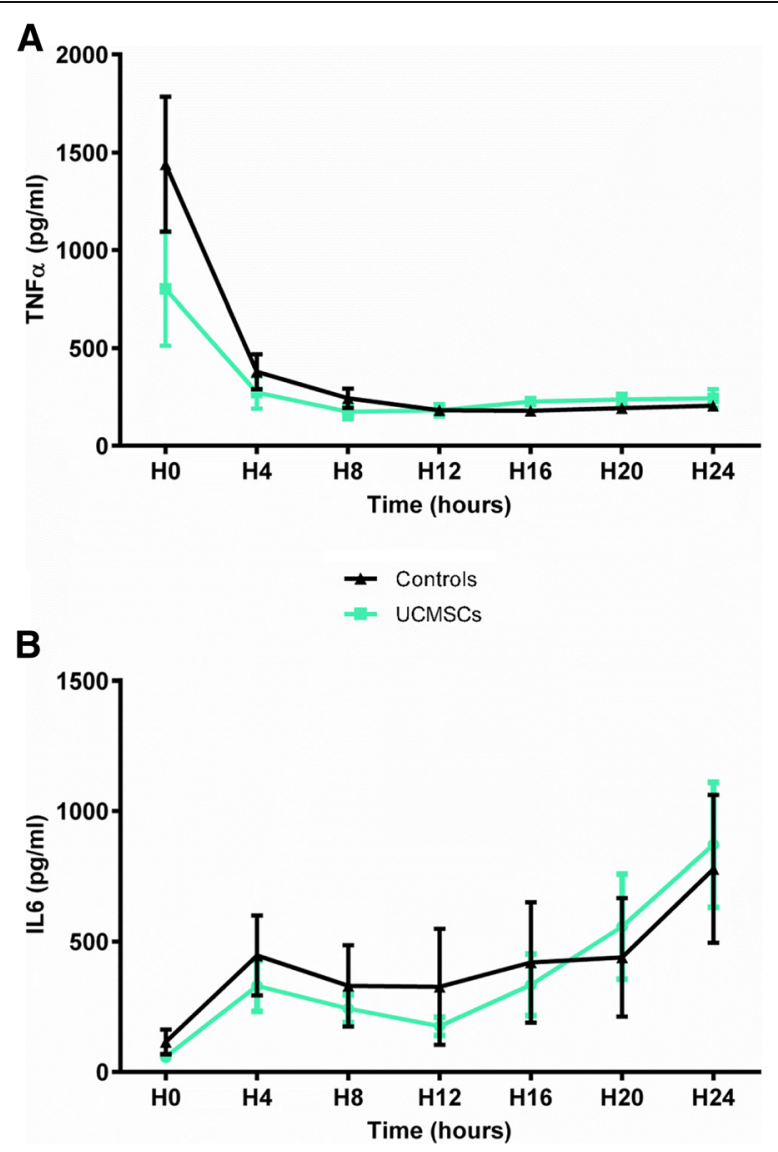

Fig. 5 UCMSCs have no effect on systemic cytokine concentrations. Plasma concentrations of TNFa (a) and IL-6 (b) were similar between groups ( $n=6$ per group)

by an experienced intensivist. UCMSCs improved survival, hemodynamic parameters (reflected by a reduced requirement for norepinephrine infusion), and organ injury. All these improvements are highly relevant from a clinical perspective.

According to previously published preclinical studies, the protective effects of MSCs are closely related to their immunomodulatory capacities. Reports indicate reduced production of pro-inflammatory cytokines and increased levels of anti-inflammatory

Table 1 Effects of UCMSCs on leukocytes and platelets count

\begin{tabular}{lllll}
\hline & HO & H8 & H16 & H24 \\
\hline Leukocytes cells $/ \mathrm{mm}^{3}$, control & $18,000(1480)$ & $11,400(1067)$ & $15,100(3342)$ & $13,333(3580)$ \\
UCMSCs & $22,900(3342)$ & $11,400(1106)$ & $12,533(1233)$ & $15,600(3323)$ \\
Lymphocytes cells/mm ${ }^{3}$, control & $5872(407)$ & $5227(729)$ & $6318(1141)$ & $4775(316)$ \\
UCMSCs & $6401(713)$ & $4502(587)$ & $4698(608)$ & $6577(922)$ \\
Monocytes cells $/ \mathrm{mm}^{3}$, control & $1639(573)$ & $1657(283)$ & $2563(926)$ & $3024(1354)$ \\
UCMSCs & $2954(806)$ & $1489(246)$ & $1518(998)$ & $2403(520)$ \\
Granulocytes cells $/ \mathrm{mm}^{3}$, control & $10,800(1973)$ & $5749(1059)$ & $8517(3162)$ & $5532(1925)$ \\
UCMSCs & $8967(1796)$ & $5750(741)$ & $4199(833)$ & $6618(2217)$ \\
Platelets / mm ${ }^{3}$, control & $391,167(36238)$ & $356,667(24503)$ & $273,667(42942)$ & $195,750(37666)$ \\
UCMSCs & $444,400(42887)$ & $369,500(45603)$ & $264,000(25923)$ & $226,400(38203)$ \\
\hline
\end{tabular}




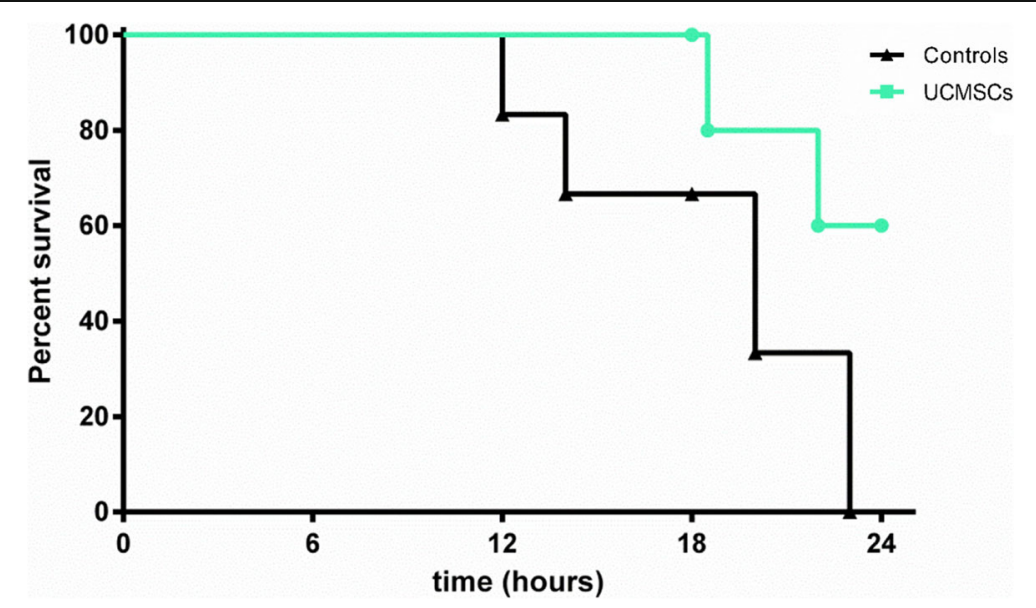

Fig. 6 UCMSCS improve survival. Survival percentages of untreated and treated pigs after induction of peritonitis are presented as a Kaplan-Meier survival curve (Log-Rank test, $p=0.08$ )

cytokines, which may modulate the innate and adaptive immune responses during septic shock [13, 16, 25-27]. Another reason advanced to explain the beneficial effect of MSCs is their antibacterial properties. Several authors demonstrated that MSC administration improves bacterial clearance by triggering increased neutrophil phagocytosis and production of antibacterial peptides such as LL-37 and hepcidin [10, 28-30]. Our results contrast with these previous findings as we did not observe any effect of MSCs on cytokine production or bacterial clearance. This discrepancy may be explained by differences between the animal models used and MSC doses. Indeed, most murine studies used very large MSC doses. For example, Song et al. [25] indicated that administration of $40.10^{6}$ MSCs/ $\mathrm{kg}$ (40-fold higher than in our study) decreased plasma levels of IL- 6 and TNF $\alpha$, increased IL-10 and improved bacterial clearance during CLP. Similarly, studies demonstrating antibacterial properties of MSC in vitro used an excess of cells relative to bacterial CFU [28, 31]. Our data indicate no antibacterial or anti-inflammatory action for UCMSC in vivo or in vitro when used at a clinically relevant dose.

However, it is surprising that despite the lack of effect on inflammation and bacterial clearance, treated pigs exhibited lower organ failure and improved survival. Indeed, the most impressive effect was observed on MAP which was better preserved with reduced requirement for vasopressors. We can speculate that this effect on vascular tone stems from a role of UCMSCs in preventing sepsis-induced endothelial dysfunction. A protective effect of MSCs on endothelial cells has recently been suggested. Yang et al. [32] showed that infiltration of MSCs protected lung endothelium from apoptosis and maintained adherens junctions in a murine model of acute lung injury. This improvement to lung permeability correlated with an increase in VEGF levels. Using the same animal model, Xiang et al. [33] observed up-regulation of VE-cadherin and catenin in MSC-treated mice. According to $\mathrm{Hu}$ et al. [34], this up-regulation tended to correlate with an increase in hepatocyte growth factor. The protective effect of MSCs could also be the result of mitochondrial transfer. Indeed, MSC can transfer mitochondria to damaged cells through intracellular nanotubes, gap junctions, and cell fusion or carried in microvesicles [35]. This mechanism appears to be related to the improvement to organ failure in various diseases. Indeed, Islam et al. demonstrated that MSC mitochondria 
transfer protects from lung injury [36]. Rocheteau et al. found an amelioration of mitochondria dysfunction in septic myopathy after injection of MSC [21]. Finally, Cselenyák et al. observed intercellular connections which save damaged cardiomyoblasts [37]. As mitochondria dysfunction is associated in sepsis patients with organ injuries and poor outcome, the MSC mitochondria transfer should be explored to explain their protective effect.

We believe that our study is particularly important in highlighting the action of MSCs during sepsis and septic shock for several reasons. First, we used a pig model of resuscitated septic shock. The use of this animal model better mimics the clinical situation than murine models both in terms of weights (40-60 kg) and cardiovascular physiology [38]. Second, we performed this study in a double-blind way to avoid bias management, and an experienced intensivist took care of the resuscitation during the whole study. Third, UCMSCs were produced in clinical grade and were used immediately after thawing, reflecting the clinical setting. This point is very important as the effect of cryopreservation on MSCs is unclear. Moll et al. demonstrated that freeze-thawed MSCs decreased response to pro-inflammatory stimuli and lowered their ability to secrete anti-inflammatory cytokines as compared to fresh MSCs [39]. Likewise, François et al. found that freeze-thawed MSCs are refractory to interferon IFN $\gamma$-induced up-regulation of indoleamine 2, 3-dioxygenase [40]. However, these authors also indicated that the immunosuppressive activity of MSCs could be restored after a 24-h culture. In contrast, Luetzkendorf et al. [41] showed that if MSCs were used immediately after thawing, they decreased the proliferation of PBMCs stimulated with phytohemagglutinin to a similar extent to fresh MSCs. Finally, Barcia et al. [42] demonstrated in a murine model of arthritis that fresh and frozen MSCs had an identical ability to decrease inflammation. Our results indicate that UCMSCs produced according to good manufacturing practice conditions, cryopreserved and administered intravenously after thawing, could protect against organ failure during septic shock.

However, this study presents some limitations. First, no antibiotics were administered nor lavage of the peritoneal cavity performed. These were deliberate choices as we wished to study a very severe model with $100 \%$ mortality, to allow us to determine the potential effects of UCMSCs in the most severe septic shock patients. Second, unlike most septic shock patients, our pigs had no comorbidities. Finally, UCs were not selected based on obstetric factors, as recently reported by Avercenc-Léger et al. [43]. Indeed, birth weight, the number of weeks' amenorrhea, placental weight, normal pregnancy, and absence of preeclampsia have all been identified as critical factors for cell expansion. Although the optimal selection criteria for UC used for MSC production for inflammation disease treatment are not yet defined, it could be interesting to select UC according to these obstetric factors as part of standardization of production procedures.

\section{Conclusion}

The results presented here show that the administration of thawed clinical-grade UC-derived MSCs significantly improved hemodynamic parameters and organ injury in a relevant pig model of septic shock and improved survival. This first study conducted in large animals indicates that UCMSCs are a promising treatment option for septic shock.

\section{Abbreviations}

CARS: Compensatory anti-inflammatory response; CFU: Colony-forming units; CO: Cardiac output; CVP: Central venous pressure; GvHD: Graft-versus-host disease; HES: Hydroxyethyl starch; IC: Cardiac index; MAP: Mean arterial pressure; 
MARS: Mixed antagonist response syndrome; MPAP: Mean pulmonary artery pressure; MSC: Mesenchymal stem cells; PAOP: Artery occlusion pressure; RAP: Right atrial pressure; SIRS: Systemic inflammatory response syndrome; UC: Umbilical cord; UCMSC: Umbilical cord-derived mesenchymal stem cells; a-MEM: Minimum essential medium alpha

\section{Acknowledgements}

The authors thank Vanessa Marie, Aude Falanga, Brice Mourer, Antoine Chalon, Mariam Chaze, Medhi Laradh, Marie Conrad, Thibault Schwartz, Moktar Mokhtari, and Alexandre Gerardin for technical assistance.

\section{Funding}

This work was supported by recurrent funding to INSERM U1116, IMoPA UMR 7365 and a grant from BPI France and La Région Lorraine.

\section{Authors' contributions}

$\mathrm{CL}$ did data collection and/or assembly, data analysis and interpretation, and manuscript writing. $\mathrm{L}, \mathrm{AB}$, and $\mathrm{CA}$ did data collection and/or assembly and data analysis and interpretation. PL, LC, FG, CC, and $\sqcup$ did data collection and/or assembly. DB did data analysis and interpretation and final approval of manuscript. LR did data collection and/or assembly, data analysis and interpretation, and final approval of manuscript. SG did conception and design, data collection and/or assembly, data analysis and interpretation, and final approval of manuscript. All authors were involved in revising the manuscript, and the final manuscript was read and approved by all authors.

\section{Ethics approval and consent to participate}

Umbilical cords were obtained from new mothers after they had signed an informed consent form in compliance with French national legislation relating to human sample collection, manipulation, and personal data protection. The collection protocol was approved by Nancy Hospital's ethics committee and the French ministry for research (No. DC-2014-2114). Experiments were performed in line with the National Institute of Health guidelines on the Use of Laboratory Animals and were approved by the University Animal Care Committee (Comité d'Éthique Lorrain en Matière d'Expérimentation Animale (CELMEA-CE2A-66) authorization no. APAFIS5674-201606141602993).

\section{Competing interests}

The authors declare that they have no competing interests.

\section{Publisher's Note}

Springer Nature remains neutral with regard to jurisdictional claims in published maps and institutional affiliations.

\section{Author details}

${ }^{1} \mathrm{CHRU}$ de Nancy, Unité de Thérapie Cellulaire et banque de tissus, 54500 Vandoeuvre-lès-Nancy, France. ${ }^{2}$ INSERM, U1116, 54500 Vandoeuvre-lès-Nancy, France. ${ }^{3}$ CNRS, UMR 7365, 54500 Vandoeuvre-lès-Nancy, France. ${ }^{4}$ Université de Lorraine, 54000 Nancy, France. ${ }^{5} \mathrm{CHRU}$ de Nancy, Service de Réanimation Médicale, Hôpital Central, 54000 Nancy, France. ${ }^{6}$ INOTREM, 54500 Vandoeuvre-lès-Nancy, France. ${ }^{7}$ EA 7300 Stress Immunité Pathogènes, 54500 Vandoeuvre-lès-Nancy, France. ${ }^{8}$ Ecole de chirurgie, 54500 Vandoeuvre-lès-Nancy, France. ${ }^{9} \mathrm{CHRU}$ de Nancy, laboratoire anatomie et cytologie pathologiques, 54000 Nancy, France.

Received: 1 March 2018 Accepted: 30 July 2018

Published online: 08 August 2018

\section{References}

1. Singer M, Deutschman CS, Seymour CW, Shankar-Hari M, Annane D, Bauer M et al (2016) The third international consensus definitions for sepsis and septic shock (Sepsis-3). JAMA 315:801.

2. Shankar-Hari M, Phillips GS, Levy ML, Seymour CW, Liu VX, Deutschman CS et al (2016) Developing a new definition and assessing new clinical criteria for septic shock: for the third international consensus definitions for sepsis and septic shock (Sepsis-3). JAMA 315:775.

3. Xiao W, Mindrinos MN, Seok J, Cuschieri J, Cuenca AG, Gao H et al (2011) A genomic storm in critically injured humans. J Exp Med 208:2581-2590.

4. van Vught LA, Wiewel MA, Hoogendijk AJ, Frencken JF, Scicluna BP, Klein Klouwenberg PMC et al (2017) The host response in sepsis patients developing intensive care unit-acquired secondary infections. Am J Respir Crit Care Med. https://doi.org/10.1164/rccm.201606-12250C.

5. van der Poll T, van de Veerdonk FL, Scicluna BP, Netea MG (2017) The immunopathology of sepsis and potential therapeutic targets. Nat Rev Immunol 17:407-420.

6. Xie M, Hao HJ, Cheng Y, Xie ZY, Yin YQ, Zhang Q et al (2017) Adipose-derived mesenchymal stem cells ameliorate hyperglycemia through regulating hepatic glucose metabolism in type 2 diabetic rats. Biochem Biophys Res Commun 483:435-441.

7. Zhao K, Lou R, Huang F, Peng Y, Jiang Z, Huang K et al (2015) Immunomodulation effects of mesenchymal stromal cells on acute graft-versus-host disease after hematopoietic stem cell transplantation. Biol Blood Marrow Transplant 21:97-104.

8. Zhu H, Xiong Y, Xia Y, Zhang R, Tian D, Wang T et al (2017) Therapeutic effects of human umbilical cord-derived mesenchymal stem cells in acute lung injury mice. Sci Rep 7:39889.

9. Mei SH, McCarter SD, Deng Y, Parker CH, Liles WC, Stewart DJ (2007) Prevention of LPS-induced acute lung injury in mice by mesenchymal stem cells overexpressing angiopoietin 1. PLoS Med 4:e269.

10. Jackson MV, Morrison TJ, Doherty DF, McAuley DF, Matthay MA, Kissenpfennig A et al (2016) Mitochondrial transfer via tunneling nanotubes (TNT) is an important mechanism by which mesenchymal stem cells enhance 
macrophage phagocytosis in the in vitro and in vivo models of ARDS: mitochondrial transfer from MSC to macrophages. Stem Cells. https://doi.org/10.1002/stem.2372.

11. Németh K, Leelahavanichkul A, Yuen PST, Mayer B, Parmelee A, Doi K et al (2009) Bone marrow stromal cells attenuate sepsis via prostaglandin E2-dependent reprogramming of host macrophages to increase their interleukin-10 production. Nat Med 15:42-49.

12. Gonzalez-Rey E, Anderson P, González MA, Rico L, Büscher D, Delgado M (2009) Human adult stem cells derived from adipose tissue protect against experimental colitis and sepsis. Gut 58:929-939.

13. Chao Y-H, Wu H-P, Wu K-H, Tsai Y-G, Peng C-T, Lin K-C et al (2014) An increase in CD3+CD4+CD25+ regulatory T cells after administration of umbilical cord-derived mesenchymal stem cells during sepsis. PLoS One 9:e110338.

14. Pedrazza L, Lunardelli A, Luft C, Cruz CU, de Mesquita FC, Bitencourt S et al (2014) Mesenchymal stem cells decrease splenocytes apoptosis in a sepsis experimental model. Inflamm Res 63:719-728.

15. Kim H, Darwish I, Monroy M-F, Prockop DJ, Liles WC, Kain KC (2014) Mesenchymal stromal (stem) cells suppress pro-inflammatory cytokine production but fail to improve survival in experimental staphylococcal toxic shock syndrome. BMC Immunol 15:1.

16. Luo C, Zhang F, Zhang L, Geng Y, Li Q, Hong Q et al (2014) Mesenchymal stem cells ameliorate sepsis-associated acute kidney injury in mice. Shock 41:123-129.

17. Mei SHJ, Haitsma JJ, Dos Santos CC, Deng Y, Lai PFH, Slutsky AS et al (2010) Mesenchymal stem cells reduce inflammation while enhancing bacterial clearance and improving survival in Sepsis. Am J Respir Crit Care Med 182:1047-1057.

18. Yagi H, Soto-Gutierrez A, Kitagawa Y, Tilles AW, Tompkins RG, Yarmush ML (2010) Bone marrow mesenchymal stromal cells attenuate organ injury induced by LPS and burn. Cell Transplant 19:823-830.

19. Rojas M, Cárdenes N, Kocyildirim E, Tedrow JR, Cáceres E, Deans R et al (2014) Human adult bone marrow-derived stem cells decrease severity of lipopolysaccharide-induced acute respiratory distress syndrome in sheep. Stem Cell Res Ther 5:42.

20. Tan L, Huang Y, Pan X, Quan S, Xu S, Li D et al (2016) Administration of bone marrow stromal cells in sepsis attenuates sepsis-related coagulopathy. Ann Med 48:235-245.

21. Rocheteau P, Chatre L, Briand D, Mebarki M, Jouvion G, Bardon J et al (2015) Sepsis induces long-term metabolic and mitochondrial muscle stem cell dysfunction amenable by mesenchymal stem cell therapy. Nat Commun 6:10145.

22. Beane OS, Fonseca VC, Cooper LL, Koren G, Darling EM (2014) Impact of aging on the regenerative properties of bone marrow-, muscle-, and adipose-derived mesenchymal stem/stromal cells. PLoS One 9:e115963.

23. Jin H, Bae Y, Kim M, Kwon S-J, Jeon H, Choi S et al (2013) Comparative analysis of human mesenchymal stem cells from bone marrow, adipose tissue, and umbilical cord blood as sources of cell therapy. Int J Mol Sci 14:17986-18001.

24. Dominici M, Le Blanc K, Mueller I, Slaper-Cortenbach I, Marini F, Krause DS et al (2006) Minimal criteria for defining multipotent mesenchymal stromal cells. The International Society for Cellular Therapy position statement. Cytotherapy 8:315-317.

25. Song Y, Dou H, Li X, Zhao X, Li Y, Liu D et al (2017) Exosomal miR-146a contributes to the enhanced therapeutic efficacy of IL-1 1 -primed mesenchymal stem cells against sepsis: IL-1 $\beta$ enhances immunomodulatory effect of MSCs. Stem Cells. https://doi.org/10.1002/stem.2564.

26. Chang C-L, Leu S, Sung H-C, Zhen Y-Y, Cho C-L, Chen A et al (2012) Impact of apoptotic adipose-derived mesenchymal stem cells on attenuating organ damage and reducing mortality in rat sepsis syndrome induced by cecal puncture and ligation. J Transl Med 10:244.

27. Wu K-H, Wu H-P, Chao W-R, Lo W-Y, Tseng P-C, Lee C-J et al (2015) Time-series expression of toll-like receptor 4 signaling in septic mice treated with mesenchymal stem cells. Shock 45:634-640

28. Krasnodembskaya A, Song Y, Fang X, Gupta N, Serikov V, Lee J-W et al (2010) Antibacterial effect of human mesenchymal stem cells is mediated in part from secretion of the antimicrobial peptide LL-37. Stem Cells 28:2229-2238.

29. Krasnodembskaya A, Samarani G, Song Y, Zhuo H, Su X, Lee J-W et al (2012) Human mesenchymal stem cells reduce mortality and bacteremia in gram-negative sepsis in mice in part by enhancing the phagocytic activity of blood monocytes. Am J Phys Lung Cell Mol Phys 302:L1003-L1013.

30. Alcayaga-Miranda F, Cuenca J, Khoury M (2017) Antimicrobial activity of mesenchymal stem cells: current status and new perspectives of antimicrobial peptide-based therapies. Front Immunol 8. https://doi.org/10.3389/fimmu.2017.00339.

31. Alcayaga-Miranda F, Cuenca J, Martin A, Contreras L, Figueroa FE, Khoury M (2015) Combination therapy of menstrual derived mesenchymal stem cells and antibiotics ameliorates survival in sepsis. Stem Cell Res Ther 6. https://doi.org/10.1186/s13287-015-0192-0.

32. Yang Y, Hu S, Xu X, Li J, Liu A, Han J et al (2016) The vascular endothelial growth factors-expressing character of mesenchymal stem cells plays a positive role in treatment of acute lung injury In Vivo. Mediat Inflamm 2016:1-12.

33. Xiang B, Chen L, Wang X, Zhao Y, Wang Y, Xiang C (2017) Transplantation of menstrual blood-derived mesenchymal stem cells promotes the repair of LPS-induced acute lung injury. Int J Mol Sci 18:689.

34. Hu S, Li J, Xu X, Liu A, He H, Xu J et al (2016) The hepatocyte growth factor-expressing character is required for mesenchymal stem cells to protect the lung injured by lipopolysaccharide in vivo. Stem Cell Res Ther 7. https:// doi.org/10.1186/s13287-016-0320-5.

35. Paliwal S, Chaudhuri R, Agrawal A, Mohanty S (2018) Regenerative abilities of mesenchymal stem cells through mitochondrial transfer. J Biomed Sci 25. https://doi.org/10.1186/s12929-018-0429-1.

36. Islam MN, Das SR, Emin MT, Wei M, Sun L, Westphalen K et al (2012) Mitochondrial transfer from bone-marrowderived stromal cells to pulmonary alveoli protects against acute lung injury. Nat Med 18:759-765.

37. Cselenyák A, Pankotai E, Horváth EM, Kiss L, Lacza Z (2010) Mesenchymal stem cells rescue cardiomyoblasts from cell death in an in vitro ischemia model via direct cell-to-cell connections. BMC Cell Biol 11:29.

38. Koudstaal S, Jansen of Lorkeers S, JMIH G, van Hout GP, Jansen MS, Gründeman PF et al (2014) Myocardial infarction and functional outcome assessment in pigs. J Vis Exp. https://doi.org/10.3791/51269.

39. Moll G, Alm JJ, Davies LC, von Bahr L, Heldring N, Stenbeck-Funke L et al (2014) Do cryopreserved mesenchymal stromal cells display impaired immunomodulatory and therapeutic properties?: therapeutic efficacy of fresh versus thawed MSCs. Stem Cells 32:2430-2442. 
40. François M, Copland IB, Yuan S, Romieu-Mourez R, Waller EK, Galipeau J (2012) Cryopreserved mesenchymal stromal cells display impaired immunosuppressive properties as a result of heat-shock response and impaired interferon-y licensing. Cytotherapy 14:147-152.

41. Luetzkendorf J, Nerger K, Hering J, Moegel A, Hoffmann K, Hoefers C et al (2015) Cryopreservation does not alter main characteristics of good manufacturing process-grade human multipotent mesenchymal stromal cells including immunomodulating potential and lack of malignant transformation. Cytotherapy 17:186-198.

42. Bárcia RN, Santos JM, Teixeira M, Filipe M, Pereira ARS, Ministro A et al (2017) Umbilical cord tissue-derived mesenchymal stromal cells maintain immunomodulatory and angiogenic potencies after cryopreservation and subsequent thawing. Cytotherapy 19:360-370.

43. Avercenc-Léger L, Guerci P, Virion J-M, Cauchois G, Hupont S, Rahouadj R et al (2017) Umbilical cord-derived mesenchymal stromal cells: predictive obstetric factors for cell proliferation and chondrogenic differentiation. Stem Cell Res Ther 8. https://doi.org/10.1186/s13287-017-0609-z.

Submit your manuscript to a SpringerOpen ${ }^{\circ}$ journal and benefit from:

- Convenient online submission

- Rigorous peer review

- Open access: articles freely available online

High visibility within the field

Retaining the copyright to your article

Submit your next manuscript at $\boldsymbol{\nabla}$ springeropen.com 